\title{
TECHNICAL EXCELLENCE: A REQUIREMENT FOR GOOD ENGINEERING
}

\author{
Paul S. Gill \\ NASA Technical Standards Program Office \\ Huntsville, Alabama 35812 \\ William W. Vaughan \\ University of Alabama in Huntsville \\ Huntsville, Alabama 35899
}

\begin{abstract}
Technical excellence is a requirement for good engineering. Technical excellence has many different ways of expressing itself within engineering. NASA has initiatives that address the enhancement of the Agency's technical excellence and thrust to maintain the associated high level of performance by the Agency on current programs/projects and as it moves into the Constellation Program and the return to the Moon with plans to visit Mars. This paper addresses some of the key initiatives associated with NASA's technical excellence thrust. Examples are provided to illustrate some results being achieved and plans to enhance these initiatives.
\end{abstract}

\section{TECHNICAL EXCELLENCE}

Technical excellence is the goal of all engineering organizations and individuals, whether in government or private industry, national or international. What do we mean by technical excellence? Most people have their own ideas and interpretation as to what constitutes technical excellence. An entry of "technical excellence" into the search page of Google produced over 28 million entries. (Anon. 2007(2)) Thus, it is evident that technical excellence is something that is of importance to a large number of organizations and people, whether in the engineering discipline or otherwise.

. According to "Mr. Webster", excellence is defined as the state, quality, or condition of excelling; superiority, with excel being defined as to be better than; surpass-to surpass or do better than others. We believe most, if not all, people would be comfortable with this definition. As Wilbur Wright, American Inventor/Aviator (18671912) stated "It is possible to fly without motors, but not without knowledge and skill".

* Manager, NASA Technical Standards Program, paul.gill@nasa.gov, Associate Fellow

** Research Professor, University of Alabama in Huntsville, vaughan@nsstc.uah.edu, Fellow 
However, given that this paper has as one primary focus to demonstrate the importance of technical excellence relative to NASA engineering, it may be good to explore some expressions that have been made concerning technical excellence. A senior NASA Marshall Space Flight Center manager (Vanhooser, 2007) has expressed technical excellence as an Agency-wide effort to ensure that well-considered and sufficient technical thoroughness and rigor are applied to NASA programs and projects under an uncompromising commitment to safety and mission success. This expression of technical excellence is further addressed by a senior NASA Headquarters manager (Scolese, 2006(1)) relative to four guiding principles to achieving technical excellence.

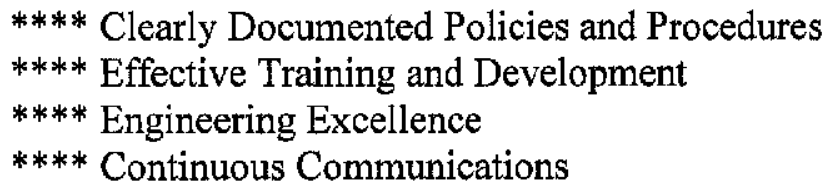

According to Scolese, 2006(2), two fundamental sets of roles and capabilities must be considered as we pursue technical excellence: (1) Personal accountability whereby each individual must understand and believe that he or she is responsible for the success of the Agency's mission and (2) Organizational responsibility to provide the proper training, tools, and environment.

As an example of how technical excellence is being stressed, the Agency's Aeronautics Research Mission Directorate has noted on the NASA Website its commitment to technical excellence, to technical accomplishments that benefit the public, and to its role as steward of the scientific and technical workforce and facilities responsible for civil aeronautics research - a key United States asset. As part of their efforts to enhance technical excellence they highlight annually aeronautics related technical accomplishments made by scientists and engineers working at the NASA centers.

The importance of technical excellence has also been noted (Anon. 2007 (1)) that due to the rapidly expanding technology and science, engineers and technologists in the $21^{\text {st }}$ century must have a strong technical background in their field and understand technology at the interface between traditional fields. They must be creative, skilled problem solvers who can think critically using sound principles and concepts.

Louis Armstrong is understood to have remarked that "If you have to ask what jazz is, you will never know". After reflecting on this remark, we have concluded there is a lot of truth in it relative to technical excellence. When one tries to quantify the meaning of technical excellence and produce some measure that those who are devoted to having metrics to use in establishing whether a particular objective or goal has been achieved, then we have some interesting observations. Does the number of patents received, professional journal publications, Ph.D.'s on staff, engineers versus nonengineers at work, positive versus negative feedbacks on products, flight vehicle successes versus failures, or profit a company makes, for example, provide a measure of 
technical excellence an organization has achieved?

In the aerospace engineering arena, one can certainly equate organizational technical excellence to mission success, at least in the eyes of the public and, for the government, the eyes of the congress. In the final analysis, technical excellence is one of, if not the most important goals of any engineering organization. How one achieves and maintains it is another question for which there is no simple answer. Unquestionably, an organization with recognized technical leadership that has vision, superior technical competence, and the desire to excel will achieve technical excellence. This technical leadership is key for the organization's success and ability of the managers assigned to carry out the organization's mission.

Technical excellence is also related to the strategic management of an organization's human capital. A recent publication (NASA Policy Directive 1000.0 "Strategic Management and Governance Handbook", August 2005) issued by the Administrator of NASA stressed the point that the excellence of its workforce is the Agency's most critical asset in accomplishing its mission. Ensuring that the Agency continues to have the scientific and technical expertise necessary to preserve the Nation's role as a leader in aeronautics, earth and space science, space flight, and technology is thus significant to achieving technical excellence, and accordingly good engineering.

While not identified by the term "technical excellence", after the very successful Saturn-Apollo program, NASA sponsored a research study was undertaken in 1974 (Dannenberg, 1974) with the hope that a few outstanding characteristics of managers or management approaches could be uncovered that would assure success for the conduct of a program. As noted in the conclusions of the report, the only "tall poles" that could be found and that could demonstrate importance to program management were these three statements:

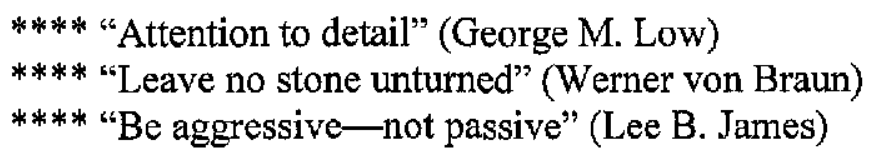

These philosophies create policies and management methods that are highly conducive to program success. Or in other words, technical excellence.

In August 2003 of the Space Shuttle Columbia's Accident Investigation Board report documenting its investigation of the February 1,2003, loss of the Space Shuttle Orbiter during re-entry (CAIB, 2003) was released. The report covered an extensive review of the investigation plus the associated findings and recommendations of the Board. One of the recommendations identified as R7.5-1 in the report reads as follows:

"Establish an independent Technical Engineering Authority that is responsible for technical requirements and all waivers to them, and will build a disciplined, systematic approach to identifying, analyzing, and controlling hazards throughout the life cycle of the Shuttle System." 
With this introduction of independent technical authorities, further emphasis was placed on the development and identification of technical excellence within the Agency's workforce.

\section{TECHNICAL AUTHORITY AND TECHNICAL EXCELLENCE}

Technical Authority is about ensuring that decisions are made balancing program pressures' with technical needs. Technical excellence is about the thoroughness and rigor of the work performed with a commitment to safety and mission success. (Vanhooser, 2007) Obviously, one endeavors to ensure that those people identified as the technical authority for a discipline also reflect the organization's people with recognized and respected technical excellence in the discipline. Thus, technical excellence is recognized by the individual's accomplishments and by the products of the organization.

Following the Columbia Accident Investigation Board actions, the NASA Chief Engineer proceeded to implement for the Agency an independent Technical Authority to set and approve technical requirements for all NASA flight programs and projects. The focus was to ensure safe and reliable operations. Technical Authority, with the responsibility to execute, was delegated by the NASA Chief Engineer to specific individuals

What are some of the attributes of an organization's culture that reflect a commitment to technical excellence and, therefore, good engineering? Instilling the following cultural attributes (Vanhooser, 2007) into all members of an organization is key to this goal.

\footnotetext{
**** Provide the highest value integrated engineering products.

$* * * *$ Believe in continual growth, learning and diversity of experience.

$* * * *$ Provide a technical conscience.

**** Leadership that is responsive and technically engaged at all levels.

***** Partnered with the programs/projects.

**** Share accountability: success and failure.

**** Proactive, engaged and predictive regarding technical content.

**** Complement and complete each other: create the winning team.

**** Recognize engineering requires versatility and mobility to meet the needs of The organization.

**** Strive to have "the right person at the right place at the right time".
}

\section{SOME EXAMPLES OF TECHNICAL EXCELLENCE INITIATIVES}

One can readily review several million examples associated with technical excellence as given under the entries for technical excellence in a Google search (Anon. 
2007(2)). It is almost over whelming at the variety of activities that have been identified and promoted on the subject within industry, government, and academia.

A recent NASA initiative on technical excellence to identify and resolve Agency engineering challenges has been undertaken by the NASA Chief Engineer (Ryschkewitch, 2007). The technical excellence initiative is designed to provide quality solutions and work that will translate into an Agency investment strategy for application to NASA's present and future missions. Some of the attributes of this initiative include improvement to NASA's overall technical capability; development of analysis/testing beneficial to multiple missions/programs/projects; and the advancement to tool/technique capability.

The Aerospace Industry last year released a position paper that argues for standards based on technical excellence rather than the source of a standard (Anon. 2006(3)). Experts from the Aerospace Industries Association's Strategic Standardization Forum prepared the position paper (Anon., 2006(2)) on the use of aerospace standards in response to growing concern that certain policies and legislation may be putting the industry-and consumers-at risk. The paper argues that aerospace industry must select standards based on safety, quality, and technical merit, rather than based on which organization developed them.

NASA's philosophy to enhance its technical excellence through the interplay of standards and their use on international missions is reflected in the following remarks by the NASA Administrator (Griffin, 2006). "One aspect of this discussion is the need to set certain engineering technical standards to ensure compatibility and interoperability in our exploration architecture. Analogous to my previous comments about spoken languages for future space explorers, it is important that the engineering standard for NASA's architecture be specified with the international metric, or SI, standards as the base unit of measure, with English units only by exception when it makes sense for NASA to do so. Thus, we hope for a high degree of compatibility of interfaces and standards, as spacefaring nations explore the Moon, Mars, and near-Earth asteroids together." Thus, the need for technically excellent standards, especially engineering technical standards, is very important to ensuring the compatibility and interoperability of exploration architectures.

\section{ROLE OF TECHNICAL STANDARDS}

Various endeavors are undertaken to ensure technical excellence. Determining how to measure and ascertain the degree to which technical excellence has been achieved is another matter. Technical standards are an integral part of technical excellence. In this regard the NASA Technical Standards Program works in close collaboration with the independent Technical Authority within the Agency.

Perhaps we should again consult "Mr. Webster" for what we mean by "standards". The term finds its use in a variety of ways, including meaning a "banner", "requirement of moral conduct", for example, plus "A degree or level of requirement, excellence, or 
attainment". It is with this last meaning that we associate technical standards and their role in technical excellence.

Technical standards are an integral part of all engineering development efforts, especially those in the aerospace industry. Designers and engineers should be among the most aggressive supporters of strong technical standards. Standardization activities establish engineering and technical applications for processes and practices and, in doing so, enhance engineering capabilities and promote technical excellence. Thus, they enable designers to not dissipate their energies on the costly exercise of "reinventing the wheel."

The motivation for technical excellence and associated development of technical standards varies considerably. One most often sees economic issues as the principal . motivation. Applications to regulatory matters are another strong motivation. International competitiveness, commodity confidence, safeguards for health, safety, and environment, reducing risks, facilitate commercial communications, and technology transfer are among the principal motivations noted for technical standards. However, enhancing engineering capabilities and technical excellence, although readily recognized as key motivations, is not often seen in the list of motivations for the development and promotion of technical standards.

Enhancing technical excellence is the key to the nation's future in the rapidly growing globalization of industry. For the United States to remain competitive and maintain its technical leadership in the world, enhancing the nation's engineering capabilities is critical to success. These capabilities can only be achieved as a result of having achieved technical excellence. This is necessary for the education of future engineers and the improvement of current engineers. Technical standards provide a major opportunity to achieve the goal of enhancing engineering capabilities and providing a means whereby technical excellence can be infused into the process. This has been one of the motivating purposes of the NASA Technical Standards Program. (Gill and Vaughan, 2006)

Enhancing engineering capabilities and technical excellence is an important value of technical standards, especially when coupled with allied information such as engineering lessons learned and experiences with use of the standard. Such is the thrust of the NASA Technical Standards Program. This thrust is being reinforced and expanded based on feedbacks from the engineering staff of NASA and its supporting contractors. This integration is one step toward the goal of significantly enhancing the engineering capabilities and technical excellence of NASA and the aerospace industry in order to meet the future demands for timely, productive, and reliable space systems, plus contributing to improved costs. (Gill and Vaughan, 2003)

\section{CONCLUDING REMARKS}

This paper has endeavored to focus on the subject of technical excellence and its importance to good engineering and to provide the reader with some information and 
motivations that will enhance their personal and organization's quest for technical excellence. Not only is the need for technical excellence a significant matter for the aerospace industry, both for government and non-government organizations, but it is equally important for the non-aerospace industry. Technical standards are an important element of technical excellence. The role standards play in achieving technical excellence includes the transfer of engineering experience, lesson learned, best practices, and infusion of new technology for the further enhancement of technical excellence within all organizations. Thus, not only do technical standards support the achievement of technical excellence, and thus good engineering, they also enable technical excellence to be passed on to others. While technical excellence is not easy to quantify, there is no doubt it is readily recognized, both by those involved in engineering activities as well as those who are the "customers", be they public, congressional, or otherwise.

\section{NASA TECHNCAL STANDARDS PROGRAM WEBSITE}

\section{http://standards.nasa.gov}

\section{REFERENCES}

Anon. 2006, "Technical Excellance", NASA Aeronautics Research Mission Directorate, URL: http:www.aeronautics.nasa.gov/technical_excellance.htm.

Anon. 2006, "Safety of Aerospace Products Demand Freedom to Select Most Appropriate Standards", Aerospace Industries Association, URL: http://www.ssfaerospace.orgl.

Anon. 2006, "Aerospace Industry Argues for Standards Based on Technical Excellance Rather Than Source", March 7, 2006, American National Standards Institute, New Your, New York (News Release).

Anon. 2007(1), "Engineering and Technology for the $21^{\text {st }}$ Century: Technical Excellance", March 16, 2007, Brigham Young University, Provo, UT.

Anon, 2007(3), "Technical Excellance", December 5, 2007, Google Search, URL: http://www.google.com.

CAIB, 2003, "Columbia Accident Investigation Board Report, Volume I", ISBN 0-16067904-4, August 2003, U. S. Government Printing Office, Washington, D.C.

Dannenberg, Konrad K., 1974, "Management Philosophies as Applied to Major NASA Programs", October 2007, University of Tennessee Space Institute, Tullahoma, TN.

Gill, Paul S. and William W. Vaughan, 2003, "Development of NASA Technical Standards Program Relative to Enhancing Engineering Capabilities", Space Technology and Applications International Forum (STAIF-2003), Conference on Human Exploration, 
Albuquerque, NM, February 2-6, 2003.

Gill, Paul S. and William W. Vaughan, 2006, "Engineering Excellence and the Role of Technical Standards", AIAA Paper Number AIAA-2006-0573, American Institute of Aeronautics and Astronautics, Reston, VA.

Griffin, Michael D., 2006, "Partnership in Space Activities", Remarks at $56^{\text {th }}$ International Astronautical Congress, October 20, 2006, NASA Press Release, 2006, NASA Headquarters, Washington, D. C.

Ryschkewitch, Michael, 2007, "RFP for Technical Excellence Initiative Cross-Cutting Issues", November 5, 2007, NASA Chief Engineer, NASA Headquarters, Washington, D.C.

Scolese, Chris, 2006(1), "Four Guiding Principles of Technical Excellence", February 8, 2006, NASA ASK OCE Newsletter, Vol. 1, Issue 4, NASA Headquarters, Washington, D.C.

Scolese, Chris, 2006(2), "Technical Excellence: Roles and Responsibilities", February 24, 2006, NASA ASK OCE Newsletter, Vol. 1, Issue 5, NASA Headquarters, Washington, D.C.

Vanhooser, Teresa, 2007, "MSFC Technical Excellence/Technical Authority", May 2007, NASA Marshall Space Flight Center, Huntsville, AL.

Prepared for presentation at the $47^{\text {th }}$ AIAA Aerospace Sciences Meeting, January 7-11, 2008, Reno, Nevada 